\title{
"THE LIVED EXPERIENCES OF CYBERBULLIED SENIOR HIGH SCHOOL STUDENTS: A UNITED ARAB EMIRATES CASE"
}

\author{
Virgimin Reyes Panganiban \\ De La Salle Medical and Health Sciences Institute vrpanganiban@dlshsi.edu,ph
}

\section{Rommel Pilapil Sergio}

Abu Dhabi School of Management r.sergio@adsm.ac,ae

\begin{abstract}
:
This research study intends to explore the cyber bullying experiences of selected students in a non-Arab High School institution in Dubai, United Arab Emirates (UAE). To carry out this intention, the researchers extracted themes in the narratives of lived experiences and analyzed transcribed interview data provided by 10 respondents who underwent a rigid pre-qualifying process of selection. The study is focused on the cyberbullying experiences of the students engaged in social networking sites in Dubai. The respondents of the study were Grade 11 and 12 senior high school students, age 15-18 years old, both male and female. Further, this study determined the emotional, psychosocial and cognitive needs presented by the respondents.The researchers used phenomenological, qualitative analysis of narrative data research design. Through purposive sampling method, ten students from the 100 targeted senior high school students were selected for in-depth interview. The participants were selected based on their experiences as a victim of cyberbullying like exclusion, denigration, masquerade, outing and discrimination.From the emerging themes, there were related theories presented in the framework focused on the emotional, psychosocial and cognitive needs of the victims of cyberbullying. The result of the study is conclusive as evident by victims of cyberbullying whose emotional, psychosocial and intellectual state of being were affected. However, they demonstrated willingness to form a support group to extend help to people of the same dilemma and further a more comprehensive and recommendatory approach on this study.
\end{abstract}

Keywords:

Lived experiences, cyberbullying, Senior High School students, United Arab Emirates, emotional, cognitive, psychosocial Article Received: 18 October 2020, Revised: 3 November 2020, Accepted: 24 December 2020

\section{INTRODUCTION}

Amidst the emergence of modern technologies is a strict religious culture in the Arab country that infuses pressure both to expatriate parents and children especially students to sustain a culture challenging and demanding lifestyle. The call of everyday survival makes majority of parents in Dubai working that allows social networking sites more available to provide alternate attention to their children whose vulnerability a potential prey to bullies. Off-guard, they become victims of cyberbullying.

School authorities in the UAE are not behind in implementing policies related to cyberbullying but the subject exists favorably to victims who have less courage to speak up on their experiences. While a preventive execution could be strengthened by closely monitoring students' activities inside the school premises,
School Administrators should exert more efforts to encourage parents to involve actively in the daily undertakings of their children. Relative to the results of the study, parents shoulder the major responsibilities to safeguard and provide greater protection for their children.

Social media became the new school hallways. In overcoming and surviving the ruthlessness of cyber bullying, the researchersare determined to help others like her to positively stand up against this threat.

Considering the research on cyberbullying, it has established that students involved are more prone to develop health problems, lower selfesteem, get poor grades and unwillingness to go to school. It is but important for the society to understand and take this type of bullying seriously. Online bullying is in itself detrimental to the point it can be done anonymously, in front 
of a vast audience, and can happen at any time of the day, week, and year.

Given the current context, it is surprising that even with the accommodating Arab culture, incidents of cyberbullying have been experienced by some High School students. Most of these incidents were not formally reported. The narrations of students, however, revealed that cyberbullying was happening. Based on personal interviews with some senior High School students in the senior grades (Grades $11 \& 12$ ), three out of five students had been the target of cyberbullying because of their physical appearance. Hence, they became afraid to mingle with others, started to isolate themselves, had a hard time to focus on their studies and did not have the courage to defend themselves.

The current school interventions take the form of preventive policies like blocking student access to social networking sites such as Facebook, Twitter, Instagram etc. The school also provides students during the summer break with activities that tackle their insights and views regarding cyberbullying. Posters, newsletters, announcements about cyberbullying, its advantages and disadvantages and on how to prevent or stop it if anyone is being bullied are exhibited in the bulletin board for students' awareness. Apparently, even with these efforts, cyber bullying still occurs.

Despite the existence of school environment policies that deter cyberbullying, individual students need to be provided with the means to be empowered to effectively address their experiences of being cyberbullied (Lee, Svanstrom, \& Dalai, 2013).

Thus, the researchers wanted to explore the painful experiences of the victims of cyberbullying, in order to understand them better and provide appropriate support that where needed.

In order to prepare better interventions and preventive policies, a deeper understanding of the unique experiences of cultural interaction is needed. The research intends to explore the cyberbullying experiences of senior High School students in the context of living in an Arab culture. The research also seeks to identify the consequent emotional, psychosocial and cognitive needs arising from the experience of cyberbullying.

\section{STATEMENT OF THE PROBLEM}

The study explored the lived experiences of cyberbullying in social networking sites among selected senior high school students in Dubai. Specifically, the study answered the following problems:

1. What are the emotional, psychosocial and cognitive needs reported by the respondents as a result of their cyberbullying experiences?

2. What counseling intervention for cyberbulliedSenior High School students may be proposed?

\section{REVIEW OF RELATED LITERATURE}

This section presents the research and conceptual literature for a deeper understanding of the study.

\section{Cyberbullying}

Cyberbullying may be defined as an act of bullying another individual, group of individuals, even an organization through the use of the Internet or other similar means (Kiran, 2013). "It has been defined as a situation when a child or teen is repeatedly distressed, threatened, harassed, humiliated, embarrassed or otherwise targeted by another child or teen using text messages, e-mails, or any other type of digital technology" (Kiran, 2013,p.28). Cyber bullying is usually manifested through continuous sending of e-mail, SMS messages, Internet-based gadgets to an individual despite the victim's' plea that he or she does not want any further contact with the bullies. Other factors related to cyber bullying are rumors, gossip, exclusion and attacks against reputations and relationships (Jackson, Cassidy, \& Brown, 2009b).

Some of the traits of cyber bullies are similar to more traditional bullies. It is important 
to note however, that there are some differences. In some instances, cyber bullies are sometimes victims of real word bullying. Thus, they want to extend their sphere of influence. Some will just want to show that they can do certain things online to show off and bully others to feel powerful (Absal, 2010).

There are similarities between traditional bullying and cyberbullying as both may cause considerable distress to the victims. Incidents usually start at school, have an impact on the school day and worst, victims are most likely to be targeted by someone they know (Agatston et al., 2012).

However, researchers have increasingly drawn nuances between the traditional definition of face-to-face bullying and the realities of cyberbullying (Smith, 2012). For instance, the fact that the victim and perpetrator are communicating in cyberspace means that there is no capacity for the perpetrator to see the victim's immediate reaction to his or her behavior (Smith, 2012b).

On the other hand, it may be that the inability to see the victim's reaction or to demonstrate one's power in front of others may make cyberbullying less appealing for those bullies who enjoy this type of feedback (Smith \& Slonje, 2010). Others, however, suggest that some bullies enjoy the anticipation of seeing the reaction or the impact of the cyberbullying at a later time (Nathan, 2009).

Many sources suggest that a single act of cyberbullying has the potential to be repeated without additional involvement of the original cyberbully due to the nature of online communication, such as, for example, forwarding a text or email message, or another online posting, which can be repeatedly viewed by large numbers of people (Dooley et al., 2009; Grigg, 2010). As such, there is a potentially larger audience of bystanders to the cyber bullying and the victim can be victimized repeatedly. In traditional bullying, we might think of physical strength, psychological, or relational dominance; however, in cyberbullying, the power differential can take different forms and may not be as crucial to defining the acts (Menesini, 2012; Nocentini et al., 2010).

"While, in terms of gender differences, the unfolding situation of cyberbullying has come to the realization that girls may be more involved as both victims and perpetrators than was previously believed in traditional bullying studies" (Salmivalli, 2010,p.49). Kowalski (2012) reviewed many studies with divergent findings as to girls' and boys' involvement. Some studies he cited suggested that girls engage in cyberbullying more than boys, which would stem from the idea that girls are more involved in indirect forms of aggression.

"While the [Arabian] Gulf lacks official statistics to evaluate the prevalence or extent of online abuses, the fact that the region has one of the world's highest internet and mobile penetration levels raises its potential risk," said Jamil Ezzo, director general of the ICDL GCC Foundation in the UAE (Bell, 2013,p.5).

"According to the I-SAFE foundation cyberbullying statistics, show that over half of adolescents and teens have been bullied online, and about the same number have engaged in cyberbullying, more than one in three young people have experienced cyberthreats online, over 25 percent of adolescents and teens have been bullied repeatedly through their cell phones or the Internet. This statistics from I-SAFE only shows that over half of young people are the victims of cyberbullying" (Bell,2013,p.13).

\section{Cultural Factors in Cyberbullying}

School bullying is recognized as a global problem with serious academic, physical, social, and psychiatric consequences (Kazarian, 2013). The objective of the present review is to inform lay and formal psychological theories proposed for the understanding of the cultural, social, personality and school-related contextual factors implicated in school bullying in the Arab world and in order to invoke the need for the advancement of national policies, research 
agendas, and school focused anti-bullying programs (Kazarian, 2013).

Peer victimization rates for 11-15 year olds in schools vary across countries with estimates ranging from $8.6 \%$ to $45.2 \%$, rates of bullying being higher for boys than girls, rates of victimization being generally higher for girls than boys, rates of peer victimization decreasing with age, and adolescents in Baltic countries reporting higher rates than those from Northern European countries (Twemlow, 2006).

Though research studies about school bullying in the Arab countries are rare, "the result of the studies made are quite alarming, as the condition of peer victimization in middle school students in 19 low- and middle-income countries (per capita Gross National Income less than US 11,455 in 2007) and reported an average prevalence rate of $34.2 \%$ for the 19 countries, and prevalence rates of $44.2 \%$ for Jordan, $33.6 \%$ for Lebanon, 31.9\% for Morocco, 39.1\% for Oman, and $20.9 \%$ for the United Arab Emirates" (Volokh, 2000).

The variance in school bullying prevalence rates reported for the Arab world is similar to variance reported for Western countries. "Nevertheless, the scarcity of school bullying studies in the Arab world makes it difficult to ascertain whether the problem is going from bad to worse or from bad to better" (Kazarian, 2013). Additional school bullying prevalence studies are required to project trends and to explain differences in prevalence rates among the different countries of the Arab world (Fleming \& Jacobsen,2009).

Studies that have examined the effects of bullying on well-being also show significant academic, physical health and psychiatric consequences to the bullied. Deterioration in academic performance (poor grades) because of the perception of the school as an unsafe place and its avoidance, and the developmental track of depression and low self-esteem that are carried to adulthood are serious consequences to victims of school bullying. (Hinduja, 2011). "Those who are being bullied, in comparison to a non-bullied control group, reporting significantly higher rates of suicidal ideation, insomnia, and feelings of sadness, hopelessness, and loneliness. Similarly, girl victims of bullying having a comparable social impairment to boys, but reporting suffering more depression and suicide than boys" (Patchin, 2011,p.291). Finally, studied bystanders of school bullying and reported that being a witness of bullying was a significant predictor of mental health problems such as somatic complaints, depression, anxiety, and substance use (Fleming \& Jacobsen, 2009).

"In addition to mental health consequences, bullying has adverse effects on physical health. Children who are bullied show higher rates of visits to health professionals and report more instances of physical health complaints, such as, headache and abdominal pain than their non-bullied peers" (Kowalski, 2007) Nevertheless, the link between bullying and risk of mental and physical ill-health is correlational. While bullying may lead to negative mental and physical health consequences, it is equally plausible that children with mental and physical health complaints may be more vulnerable to bullying (Agatson, 2012,p.84).

Empirical research on the consequences of bullying in the Arab world is scarce. The World Health Organization Global School-based Student Health Survey on middle school-aged children (usually between 13 and 15 years of age) from several Arab countries (Jordan, Lebanon, Morocco and the United Arab Emirates) showed bullied students reporting significantly higher rates of sadness and hopelessness, loneliness, insomnia and suicide than a non-bullied control group of students (Campbell,2011).

\section{Effects of Cyberbullying}

According to Kiran (2008), one of the main causes of teen suicide in the west is "cyber bullying", thus, it is only proper for private schools, parents organizations to take proactive 
steps now to address the issue before it becomes a full-blown problem.

The effects of cyberbullying appear with greatest intensity and frequency among the bullyvictim groups. They feel less safe at school, feels uncared for by teachers, has lower self-esteem, has more suicidal thoughts and is more likely to attempt suicide (Patchin \& Hinduja, 2011, 2012a).

"It was also reported that girls were more likely to experience certain forms of cyber bullying (gender-based harassment, exclusion, having personal information about them posted online) and to be more negatively impacted by the messages" (Kowalski, 2013,p.49). Girls reported with greater frequency that they felt their reputation was affected by the cyber bullying they experienced, that their concentration was affected, that it influenced their ability to make friends, that it made them want to bully back, and that it induced suicidal thoughts (Patchin, 2012).

"In a study of university students who had been victims of cyber-harassment, it was noted the following impacts: anger, sadness, hurt, embarrassment, anxiety, fear, crying, blaming themselves, poor concentration, low academic achievement, and absenteeism" (Juvonen \& Gable 2002,p.67).

\section{Cyber bullying Preventions and Interventions}

Coping strategies are responses (behaviours, emotions, cognitions) that are successful (or unsuccessful) against cyberbullying (Perren et al., 2012). These include preventing cyberbullying by reducing the risks, combating cyberbullying, and buffering its negative impacts. While there is a body of work that describes what coping strategies are being used, the evidence base for successful strategies is very limited when addressing cyberbullying (Perren, Mare'es \& Petermann, 2012). "Psychological service providers, teachers, and school administrators should consider the distinctions discussed below regardless of which phase of planning or implementation they are currently undertaking in order to address cyberbullying with their students.
Many of the coping strategies focus on the individual victims; however, there are reasons to take a wider view and adopt strategies at the school level and beyond" (Perren, 2012,p.89).

At this moment, there are many antibullying websites and programs that are intended for teenagers, parents, and school authorities. "However, adolescents often do not want to talk to adults about their cyberbullying experiences as they are afraid to do so" (Aricak, Siyahhan, Yilmaz, Memmedov, 2008,p.202).

"Social support can encompass emotional support and instrumental support but does raise the question of the ability of the helpers to offer adequate support" (Hinduja, 2012). Some of the coping strategies used or suggested in the literature include what could be described as passive strategies - do nothing, ignore it, avoid the website or the bully itself (Tokunaga, 2010).

"Beyond merely teaching about cyberbullying, the curriculum should focus on empowering students in terms of digital literacy, technological skills, critical thinking skills, net ethic, e-safety, assessing their own online risks, measures to protect themselves, their reputation, and their privacy online" (Marczak \& Coyne, 2010,p.45). Rather than trying to remove all risks which is difficult to do, it would be better to help students cope by strategizing with them about how to avoid harm (Collier, 2012,p.78).

It was suggested by Brighi (2012) that school should have a class websites wherein students and teachers are both users and producers; enabling online exchanges and collaboration on learning activities with other classes, schools and families; and the use of forums, wikis, and blogs, are all ways in which information and communication technologies can enhance the classroom experience.

Additionally, the curriculum should include an emphasis on fostering empathy and positive self-esteem. Empathy education - both cognitive and affective empathy, especially for boys, should be part of the curriculum (Topc \& Erdur-Baker, 2012). It is also suggested that 
prevention and intervention for traditional bullying and cyberbullying should not be identical since empathy stems from feedback from the victim, which is not consistently and readily available online (Topc \& Erdur-Baker, 2012). 'Work on creating positive self-esteem in students' was found to be among top three best solutions to cyberbullying suggested by students in two separate surveys (Cassidy et al., 2011). Bystanders also would benefit from empathy education because, if they understand suffering, they are less likely to inflict it (Davis \& Nixon, 2012). A distinction from traditional forms of bullying is that there is a wider variety of ways in which a person may become a cyberbullying bystander" (Agatston, 2012). As such instances, they may be the bully at the time of posting or sending the offending message or image, they may be the victim when he or she receives it, they may be with neither but have the message forwarded to them, or they may visit a website where the cyberbullying has been posted or is occurring (Li, Smith, \& Cross, 2012).

It is without saying that prevention is key; however, the importance of this saying is not realized early enough. The prevalence of bullying in primary schools points to the need for prevention and intervention programs to start early (Tangen \& Campbell, 2010).

Legal protection in addressing the existing threat of cyberbullying in the UAE schools led the President, His Highness Shaikh Khalifa bin Zayed Al Nahyan, to issue a federal legal decree on combating cyber crimes, that will provide legal protection of privacy of all information published online, including all data and informations (Wam, 2012).

Nowadays, even younger children and preschoolers, are becoming conversant with technology. Teacher and psychological service provider education and engagement with the online world are necessary. Students view most adults as unknowledgeable about cyberbullying and the online world in general, a perception validated by studies done with educators (Cassidy et al., 2009, 2012). Some students are unlikely to tell school personnel if they do not think that they can help them. Thus, school personnel requires further education and training regarding engaging in the digital world, a commitment in this area, as well as the design and development of collaborative interventions involving psychological service providers, teachers, parents, and youth, are needed (Tangen \& Campbell, 2010). It was also suggested that a training manual for educators include: Information about the basics of cyber bullying; a practical orientation; information about training skills and strategies for diagnosis and intervention; a focus on narratives; and multimedia resources. (Cassidy et al., 2012a, Sakellariou et al., 2012).

It has been argued that policy issues for cyberbullying involve tensions between the values of freedom of speech, the best interests of the child, and parental and school protective authority over the child (Grigg, 2011). Moreover, the complexity of the problem, in addition to its inherent conflicting values, requires the development of effective policy as a collaborative effort, involving all the stakeholderspolicymakers,school officials, parents, and teenagers (Brown, Jackson, \& Cassidy, 2006). Indeed, the need for a clear school policy against cyberbullying derived from a process that involves administrators, psychological service providers, teachers, students, and parents has been emphasized by a number of researchers in the area (Ja“ger et al., 2010; Willard, 2012).

\section{Emotional, Psychosocial and Cognitive Needs of Cyberbullying victim}

The upturn of cyberbullying is a frequent cause of emotional disturbance in children and young people. "The situation is complicated by the fact that these interpersonal safety issues are actually generated by the peer group and in situations that are difficult for adults to control" (Hinduja, 2011,p.88). Traditional face-to-face bullying has long been identified as a risk factor for the social and emotional adjustment of 
perpetrators, targets, and bully-victims during childhood and adolescence (Osteman, 2006).

Most research consistently identifies the consequences of bullying for the emotional health of children and young people. Victims experience a lack of acceptance in their peer groups, which results in loneliness and social isolation (Hinduja \& Patchin, 2011) .The young person's consequent social withdrawal is likely to lead to low selfesteem and depression. Studies among children and adolescents indicate moderate to strong relationships between being nominated by peers as a bully or a victim at different time points, suggesting a process of continuity (Salmivalli, 2010).

As pointed out by Harris and Petrie (2002), adding the trauma of victimization to this already vulnerable time period of adolescence can lead to a "downward spiral" for many youngsters. This was illustrated by the example of a bullying situation that ended tragically when a thirteenyear-old female shot herself in front of her classmates; her parents blamed the suicide of her severe depression which they believed was related to chronic mistreatment by fellow students (Bogan, 2002).

School climate has been found to bear a significant relationship with students' well-being, learning, and behaviour (Hinduja \& Patchin, 2011). Schools that adopt an ethic-of-care model based on a holistic approach, offering students unconditional positive regard, modelling, dialogue, and practice in ethical caring, have much to teach us about addressing problem behaviours in school (Noddings, 2005).

\section{METHODOLOGY}

The researchers used phenomenological research design. A phenomenological research study attempted to understand people's perceptions, perspectives and understandings of a particular situation or phenomenon (Van,2005).

The goal of qualitative phenomenological research is to describe a "lived experience" of a phenomenon. This phenomenological research studied the experiences of cyberbullying in social networking sites of senior High School students and tried to answer the question 'What is it like to experience being in a situation where nobody seems to like and accept you?'.

In a qualitative analysis of narrative data, which this study used, methods in analyzing the data are far different from a traditional or quantitative method of research (Waters, 2013).

The general population consisted of 100 senior high school students studying in Dubai, aged 15-18 years old. The participants were selected based on their experiences as a victim of cyberbullying like exclusion, denigration, masquerade, outing and discrimination.

In the first stretch of the research, the researchers conducted an online survey about cyberbullying. A total of 100 respondents (23 male and 77 female) answered the survey. To be included in the interview phase of the study, the researchers selected a respondent whose response appeared frequently in the likert scale in items no. 6, 9, 12, 15, 18, 21, 22 and who answered Yesin item 27 in the Cyberbullying Online Survey. A total of ten students qualified for the interview who exhibited similar experiences related to cyberbullying.

The research used two instruments for the study. First, the researchers used and adapted the cyberbullying survey form constructed by the Center for Safe and Responsible Internet Use (2006). Designed by Nancy Willard, the survey was used with the middle high school students to seek information on issues focused on the respondent's experiences and exposure over the social networking sites.

The adapted cyberbullying survey includes the background and profile of the participants/respondents, and duration of internet usage. The survey also included 53 items used to determine the participants of the study. Students whose response appeared frequently in the likert scale in items $6,9,12,15,18,21,22$ and who answered Yes in item 27 were selected for interview. 
Second, an interview guide with nine questions related to cyberbullying was used. The nine item open-ended questions (please see appendix B) for the interview revolved around the topic of their cyberbullying experiences and the resulting consequences they went through.

The first step taken was preparation to disseminate information in a form of letter sent via online to the administrators, parents, teachers and staff for the administration of questionnaire and survey.Second, after consent to participate in the survey have been received, the researcherssent the online link to the participants. The link was put active for a period of one month. At the end of the onemonth period, it was deactivated for tabulation and analysis.

Third, from the survey group, ten students were selected (on the basis of their high scores in the Cyberbullying survey) for an in-depth interview regarding their cyber bullying experiences. A pre-information consent letter was given to the ten participants to inform their parents that they will be part of the interview with a clear goal and objective on how and why they were selected and assured the parents that the information gathered would be kept confidential.

The interview with the ten participants lasted for 1-2 hours within the school premises. Included in the interview process is the establishment of rapport with the participants. As the interview progresses, the participants unrestrictedly shared their experiences and expressed their needs.

After getting through the interview, the researchersassessed and assisted the participants by referring them to the School Counselor for further management of their cyberbullying experiences. When the researchers got assured that the participants' counseling needs had all been addressed, the researchers acknowledged and expressed gratitude for their participation.

Transcribed interview is the primary data analyzed in this study. From the interview data, the researchers extracted themes in the narratives of lived experiences given by respondents. The researchers also related the themes with theories presented in the framework that focused on the emotional, psychosocial and cognitive needs of the victims of cyberbullying. As the goal in phenomenological research was to describe participants' lived experiences, the researchers chose to expand on the themes and relate them to similar experiences discussed and described by the participants (Waters, 2013).

\section{RESULTS AND DISCUSSION}

Problem 1. What are the emotional, psychosocial and cognitive needs reported by the respondents resulting from their cyberbullying experiences?

Based on the narrated experiences of the participants in the presented table, the respondents' statements could be generally described as comprising experiences pertaining to denigration, exclusion, and alienation. Common to the narration of the respondents are situations where they received frequent harmful cruel and untrue statements from cyber bullies. They also experienced being excluded in the online group and nobody wanted them to be part of any group. The respondents also narrated being alienated and felt that nobody wanted them to be in school.

Further, based on the gathered information given by the respondents, the common reason of bullying is due to physical appearance and the way they carry themselves.

In terms of emotional needs, three out of ten had a feeling of insecurities while five out of ten showed tendency to have low self-esteem, as expressed by Respondent 3, "I'm not always giving my best believing I can't make it and afraid to be judged again". All of them exhibited increased anxiety and difficulty in expressing themselves to the group.

Salmivalli (2010) pointed out the consequences of bullying for the emotional health of children and young people. He said that victims experience lack of acceptance in their peer groups, which results in loneliness and social isolation. The young person's consequent social withdrawal 
is likely to lead to low self-esteem and depression. It was also pointed out by one of the participants during the course of interview, that she was able to study and observed the behavior of the bullies. According to her, bullies are more likely to engage in a range of maladaptive and antisocial behaviours than non-bullies, bullies also have high risk of depression and suicidal ideation.

On psychosocial needs, most of the participants shared that because of cyberbullying, they had the tendency to isolate themselves to avoid taking part in any social activities. Respondents 1,2, 3, 5 disclosed that they tend to have a need for belongingness, to be accepted by peers and other people. Respondent 10,mentioned, "I did not deserve to be excluded in the group, I wasn't deep inside a bad person at all."

As pointed out by Harris and Petrie (2002), adding the trauma of victimization to this already vulnerable time period of adolescence can lead to a "downward spiral" for many youngsters. Respondent 4 said that because of cyberbullying, "I became self-conscious and sensitive to the comments of other people about me". Furthermore, Bogan (2002) mentioned that because of the bullying experiences of the respondents, most of them tried to commit suicide during the time they were emotionally affected because of bullying.

The respondents mentioned the existence of cyberbullying, as their experiences were not just a mere myth but real stories that will negatively impact the lives of people involved, and to a greater extent to those who are passive individuals. This was pointed out by Bickham and Rich (2012) that most victims of cyberbullying are often blaming themselves and feel unwanted in the place they lived in.

Victims of cyberbullying experience lack of acceptance from their peer groups which results to loneliness and social isolation. The young person's consequent social withdrawal is likely to lead to low self-esteem and depression (Salmivalli, 2010).
In cognitive needs, almost all of the participants experienced irrational thoughts Respondents 1, 3 and 7 tended to have suicidal tendencies, five of the respondents said that they were easily affected by what others thought about them and became paranoid.

There were eight of them with low academic performance (as pointed out by Respondent 7: "I was an achiever of the class but because of being excluded in the group, my academic performance was badly affected").

School climate has been found to bear a significant relationship with students' well-being, learning, and behavior (Hinduja \& Patchin, 2011). Schools that adopt an ethic-of-care model based on a holistic approach, offering students unconditional positive regard, modeling, dialogue, and practice in ethical caring, have much to teach us about addressing problem behaviors in school (Noddings, 2005).

In support to all shared experiences and reported needs, studies that have examined the effects of bullying on well-being also show significant academic, physical health and psychiatric consequences to the bullied person. Deterioration in academic performance (poor grades) because of the perception of the school as an unsafe place and its avoidance, and the developmental trajectory of depression and low self-esteem that are carried to adulthood are serious consequences to victims of school bullying (Hinduja \& Patchin, 2011).

Another factor seen in the study was gender differences. Based on the number of participants, out of ten participants only one male participated in the study. In support of this result, Kowalski et al. (2012a) mentioned that the emergence of cyberbullying has come to the realization that girls may be more involved as both victims and perpetrators than was previously believed. In traditional bullying research, they also reviewed many studies with divergent findings as to girls' and boys' involvement. Some studies he cited, suggested that girls engaged in cyberbullying more than boys, which would stem 
from the idea that girls were more involved in indirect forms of aggression.

In the analysis, cyberbullying affects the total well-being of a person especially if these cases are not being addressed by the victim's family and/or school authorities. As, mentioned in the study of Hinduja and Patchin (2011), cyberbullying resulted suicidal thoughts and actions. Hence, cyberbullying of all forms of adolescent peer aggression must be taken seriously - both at school and at home. As such, counselors and parents must continually monitor the online and offline behaviors of youth to reinforce the good actions and regulate the bad behavior in order to minimize the cases of any sorts of bullying.

Most cases of the victims of bullying in this study were related to rumors, gossip, exclusion and attacks against the reputations and relationships, which are common forms of both relational aggression and cyberbullying as mentioned in Jackson, Cassidy, and Brown (2009b).

\section{Problem 2. Based on the findings, what counseling intervention may be proposed for cyberbullied seniorHigh School students?}

After gathering all the information from the respondents' experiences and point of views, the following counseling intervention for cyber bullied senior High School students are proposed (see table in previous page).

It was clearly shown in the result and analysis of all the data gathered from the respondents that the emotional and social problems arising from cyberbullying are issues that can be addressed through counseling. Thus, counselors, whose duties are to advocate on behalf of school community, have equal responsibility to help students and parents outdo this growing issue.

The foremost emotional need manifested by the respondents in the interview are insecurities, low self-esteem and increased anxiety. Respondents 1, 3 and 7 expressed statements like "I'm not always giving my best believing I can't make it and afraid to be judged again. 'In addressing these needs, the counseling intervention should focus on activities like CBT Therapy- Assertiveness training and relaxation exercises to help them develop their self-esteem, lessen the feeling of anxiety and be able to handle their emotions positively. Furthermore, students should be educated about cyberbullying and discuss strategies for reacting to cyber bullying as targets and as bystanders. The intervention should promote empathy, ethical decision-making skills, and respect among students and increase awareness of Internet safety strategies among students and their families.

Another strategy that can be utilised by the counselor is to design a program for the need for empathy. The young people in this study felt that it was important for bullies and their followers to see how victims suffer. They assumed that a design feature that could make pain and sadness concrete would lead to bullies self-regulating their bullying behavior. Through Facebook, a group of students can use unhappy posts, sad songs, or emoticons by the victims on Facebook, believing that bullying would not happen if the bullies realized they're wrong. This realization would come if bullies can actually see that they're causing this pain. While Facebook posts, sad music, and the use of emoticons are not new design ideas, it does suggest the need for a more emotive social media environment and implore the question as to whether there is a better way to bring these elements in place, to make them more apparent and more meaningful to others viewing the social media spaces of those who are bullied.

These proposed activities are supported by Davis and Nixon (2012), who pointed out that there is a need to increase individual selfawareness and accountability. Students must be given the opportunity to practice those empathetic responses and not to live in fear and distress due to an unpleasant environment. Developing healthy behaviors and social skills more broadly should be part of the overall curriculum of the school. 
As also discussed by Hinduja and Patchin (2010), the victims of cyberbullying exhibit the following behaviors: experiences anxiety when email or instant messages appear on the computer screen, appears upset or depressed after using computer, suddenly stops using computer, appears anxious about going out in public including school, tries not to engage in conversations about what he or she is doing on the computer, and seems withdrawn from social and family support systems. These behaviors were clearly mentioned by the respondents of this study.

Cyberbullied students are unlikely to tell school personnel about their experiences, as they think they can not help them. Tangen and Campbell (2010) believe that the school personnel requires further education and training regarding engaging in the digital world to further understand the situation of the victims of cyberbullying. A commitment to professional development in this area, as well as the design and development of collaborative interventions involving psychological service providers, teachers, parents, and teenagers, are needed. Schools can provide a training manual for educators that will include; Information about the basics of cyber bullying, a practical orientation, information about training skills and strategies for diagnosis and intervention, a focus on narratives, and multimedia resources (Cassidy (2012).

The foremost psychosocial need manifested by the participants during the interview was isolation, the need for belongingness and acceptance. Respondent 10 expressed this in her statement: "I did not deserve to be excluded in the group, I wasn't deep inside a bad person at all." In addressing these needs, the counseling intervention should focus on activities like building a support group system to establish trusting friendships towards other people.

The suggested program aims at increasing adults' and students' awareness of problems of peer aggression and victimization and it tries to enhance active involvement in solving bully/victim incidents. In line with this, the anti- bullying program may consist of three modules focused on the social system, i.e., teachers, nonteaching staff, parents and the peer group and students as well who are directly involved in bully/victim problems. This program can be done by doing a self-report bullying inventory which measures levels of bullying and being bullied and social isolation and life in school checklist, which will focus on verbal, physical and direct aggression.

These proposed activities are supported by Cassidy et al. (2009,2011), Smith, (2012) and Perren et al. (2012). Social support is probably the coping strategy with the best indicators of success. Social support can encompass emotional support and instrumental support, but does raise the question of the ability of the helpers to offer adequate support. Interventions targeted at empowering support networks, bystanders, and peers may provide the greatest likelihood of success.

Teachers, Psychological Service Provider Education and engagement with the online world are necessary. Students view most adults as unknowledgeable about cyberbullying and the online world in general. Respondent 3 shared: "My parents had no idea about everything and what was going on with me in the cyber space unless I would tell them so they won't keep me grounded from using the internet."

The predominant cognitive needs manifested by the participants during the interview were irrational thoughts and deteriorating academic performance. Respondent 7, expressed this in her statement: "I was an achiever of the class but because of being excluded in the group, my academic performance was badly affected").

In addressing these needs, the proposed counseling intervention will focus on topics on Rational Emotive Therapy that will help students think logically and to understand the idea that subconscious destructive behaviors are consciously acknowledged and then subverted in favor of more constructive behavior. Further, it should 
create study skills and achievement motivation group that will develop their study habits and always be focused on their studies.

As what pointed out by the respondents, one of the main reasons why they tend to skip classes was due to painful experiences in school. Hence, another program that can be done in school is to create and establish a positive environment. This can be implemented by including in the classroom curriculum the following components: self-concept, social and emotional positive actions for managing one's responsibility, and positive actions directed toward physical and mental health, honesty, getting along with others, and continuously improving oneself. The program will also include teachers, counselors, and parents.

These proposed activities are supported by Patchin and Hinduja (2011), that students should feel comfortable approaching adults in the school to discuss problems and be motivated to attend schools. Brighi (2012) also suggested a class website where students and teachers are both users and producers, enabling online exchanges and collaboration on learning activities with other classes, schools and families; and the use of forums, wikis, and blogs, which are all ways in which information and communication technologies can enhance the classroom experience.

Moreover, as expatriates in an Arab country particularly in Dubai, some senior High School students are hesitant to disclose their personal dilemmas. As such, parents raising their children in Dubai need to be more vigilant and hands-on with their children despite the fact that they are devoting most of their time in their work. Respondent 3: "Both my parents are working. We have limited time to talk and discuss personal matters related to me why during the time I got bullied, I just kept everything to myself.",

Most students are better prepared than adults in communicating technologically (Blair, 2003). It was obviously shown that technology and its misuse by students create challenges for school counselors, teachers, administrators, and parents (Franek, 2006). School counselors are not the only people in the school who are responsible for the safety of students, but they may be the primary contact person for parents and students seeking information or help. Providing leadership for students, faculty, administrators, and parents in addressing the topic of cyberbullying may be an important step in ensuring students' safety. Advocating for the implementation of school policies with regard to cyberbullying and collaborating with other school personnel to design and implement prevention and intervention programs may serve to strengthen school counselors' efforts in preventing cyberbullying.

Currently, the Crown Prince of Abu Dhabi Sheikh Mohammed Bin Zayed, suggested to all the UAE Schools to introduce "moral education" in school curriculums. The initiative aims to instill ethical values in UAE school students and to promote such concepts as tolerance, respect, and community participation. In connection with this, Dr. Al Nuaimi said the challenges of the $21 \mathrm{st}$ century required government, educators and parents to work together to teach ethics and community values to young people, and build an educated, cultured society, as young people should learn not to look down on each other, understand that all humans are equal and they must learn to respect the different opinions (Dajani, 2016).

Hence, the researchers believe that if moral education subject can be included in the school curriculum, it will be an effective tool to minimize the problems related to cyberbullying.

\section{CONCLUSION}

After gathering and analyzing the data, the following conclusions had been drawn:

Victims of cyberbullying are affected emotionally, psycho socially and intellectually as evident by the results of the study. It would have been passe' to stress but the researchers strongly believes parents have major responsibilities to safeguard and provide greater protection for their 
children. There is nothing as painful experience for children as being bullied, taken for granted and struggles at the same time to live as normal human beings, finding more ways than one to uplift their morale and become better individuals.

School authorities are not behind in the implementation of policies related to cyber bullying but the subject exists favorably to victims who have less courage to speak up on their experiences to school administrators and staff.

The school is one major area where the preventive execution could be strengthened by closely monitoring students' activities inside the school premises and by exerting more efforts to encourage parents to involve actively in the daily undertakings of their children. Majority of parents in Dubai are focused on their careers to support their children's everyday needs. The society, coupled with the current technologies are pressure for parents to work doubly hard just to make both ends meet. Spending much time working means spending less quality time with their children to address their personal problems and needs. However, victims of cyberbullying showed willingness to form a support group to extend help to people of the same dilemma.

\section{RECOMMENDATIONS}

The following recommendations are proposed:

First, creation of support group system for all victims of any sorts of bullying will be helpful in overcoming their painful experiences. Through this system, students will have more rooms to share their cyberbullying thoughts, views and experiences and may contribute better solutions to the problem as there will be support and guide from among members of the group.

Secondly, the School Counselor can organize and facilitate activity to raise awareness on the warning signs related to cyber bullying where parents, students and teachers are the major participants. The researchers recommends these three (parents, students and teachers) to be the subjects in resolving issues related to bullying.
The objective of which is to minimize incidents of bullying if not to eradicate.

Lastly, more in-depth and extensive studies on cyberbullying may be initiated as this researchers' study is limited to the selected senior High School students in Dubai.

\section{REFERENCES}

[1] Absal, R. (2010). Cyber-bullying is the new domain in cruelty. Retrieved from www.thegulf news.com

[2] Agatston, P., Kowalski, R., \& Limber, S. (2012). Youth views on cyberbullying. New York, NY: Routledge.

[3] Arianna, A. (2010). Arab Values and Attitudes. Retrieved from www.thegulf news.com

[4] Aricak, T., Siyahhan, S., Uzunhasanoglu, A., Saribeyoglu, S., Ciplak, S., Yilmaz, N., Memmedov, C. (2008). Cyberbullying among Turkish adolescents. Cyberpsychology in Behavior.

[5] Bell, J. (2013). U.AE-wide campaign to protect children from cyberbullying. Retrieved from www.thenational.uae.

[6] Beran, T. N., Rinaldi, C., Bickham, D. S., \& Rich, M. (2012). Evidence for the need to support adolescents dealing with harassment and cyber-harassment: Prevalence, progression, and impact. School Psychology International.

[7] Blair, J. (2003). New breed of bullies torment their peers on the Internet. Education Week. Center for Safe and Responsible Internet Use.

[8] Bogan, J. (2002). Dad says girl battled depression; Teasing at school preceded suicide, he says tearfully. San Antonio Express.

[9] Boyd, D. (2006). Friends, Friendsters, and MySpace Top 8: Writing community into being on social network sites.

[10] Campbell, M. A. (2005). Cyber bullying: An old problem in a new guise? Australian Journal of Guidance and Counselling. 
[11] Carpenter, Z. \& Rowley, LLP (2015). Effects of Cyberbullying on Teenagers More Serious than You'd Think.

[12] Cassidy, W., Brown, K., \& Jackson, M. (2012). 'Making kind cool': Parents' suggestions for preventing cyberbullying and fostering cyber-kindness. Journal of Educational Computing Research.

[13] Cassidy, W., Brown, K., \& Jackson, M. (2012b). 'Under the radar': Educators and cyberbullying in schools. School Psychology International.

[14] Coloroso, B. (2004) The Bully, the Bullied, and the Bystander. Retrieved from url.schools.hcdsb.org.

[15] Collier, A. (2012). A 'Living Internet': Some context for the cyberbullying discussion. New York, NY: Routledge.

[16] Cowie, H. (2013). Cyberbullying and its impact on young people's emotional health and well-being.

[17] Crane, K. A. (2014). Beat The Bully. Retrieved from www.timeoutdubai.

[18] Cross, D., Shaw, T., Hearn, L., Epstein, M. Monks, H. Lester, \& Thomas L. (2009). Australian covert bullying prevalence study.

[19] Dajani, H. (2016) Moral education to be introduced to UAE school curriculums. Retrieved from www.thenationaluae.

[20] Davis, S., \& Nixon, C. (2012). Empowering bystanders. In J. W. Patchin, \& S. Hinduja (Eds.), Cyberbullying prevention and response. New York, NY: Routledge.

[21] Dooley, J. J., Pyz_alski, J., \& Cross, D. (2009). Cyberbullying versus face-to-face bullying: A theoretical and conceptual review. Journal of Psychology.

[22] Fleming, L., Jacobsen, K. (2009). Bullying among middle-school students in low and middle income countries. Health Prom Int.

[23] Franek, M.(2006).Foiling cyberbullies in the new wild west. Educational Leadership.

[24] Gregory, J. (2004) Pupils face suspension for phone 'bullying'. The Courier Mail.
[25] Grigg, D. W. (2012). "Definitional Constructs of Cyber-bullying and

[26] Cyber-aggression from a Triangulatory Overview: A Preliminary Study into Elements of Cyber-bullying. Journal of Aggression, Conflict and Peace Research.

[27] Hoff, D.L., Mitchell, S.N. (2009). Cyberbullying: Causes, effects, and remedies. J. Educ. Adm.

[28] Isenberger, E. (2010). Causes For Counseling: The Degree To Which Cyber Bullying Affects Mental Health.

[29] Juvonen, J., Gross, E.F. (2008). Extending the school grounds?-Bullying experiences in cyberspace. J. Sch. Health.

[30] Kazarian, S. (2013). School Bullying in the Arab World: A Review. The Arab Journal of psychiatry.

[31] Kiran, C. (2013). There's nothing funny about cyber bullying. Retrieved from www.thekhaleejtimes.

[32] Knack, J., Jensen-Campbell, L., Baum, A. (2011). Worse than sticks and stones? Bullying is associated with altered HPA axis functioning and poorer health. Brain Cognition.

[33] Kowalski, R.M., Limber, S.P. (2007) Electronic Bullying Among Middle School Students. J. Adolesc. Health.

[34] Kowalski, R. M., Sue, L., and Agatston, P. W. (2012). Cyberbullying: Bullying in the Digital Age. Malden, MA: Wiley-Blackwell.

[35] Lee, M. S., Wu, Z.P., Leif, S., and Koustuv, D. (2013). Cyber Bullying Prevention: Intervention in Taiwan. Ed. James G. Scott. Plos One.

[36] Main, K. (2006). Love to Know: Arab Culture and Values.Retrieved from www.gulfnews.com

[37] Marczak, M., \& Coyne, I. (2010). Cyber bullying at school: Good practice and legal aspects in the United Kingdom. Australian Journal of Guidance and Counselling.

[38] Menesini, E. (2012). Cyberbullying: The right value of the phenomenon. Comments 
on the paper 'Cyberbullying: An overrated phenomenon?'. European Journal of Developmental Psychology.

[39] Monks, C. P., Robinson, S., \& Worlidge, P. (2012). The emergence of cyberbullying: $A$ survey of primary school pupil's perceptions and experiences. School Psychology International.

[40] Nathan, E. (2009). Reputational orientations and aggression: Extending reputation enhancement theory to upper primary school aged bullies.

[41] Nocentini, A., Calmaestra, J., SchultzeKrumboltz, A., Scheithauer, H., Ortega, R., \& Menesini, E. (2010). Cyberbullying: Labels, behaviours and definition in three European countries. Australian Journal of Guidance and Counselling.

[42] Noddings, N. (2005). The challenge to care in schools: An alternative approach to education. New York, NY: Teachers College Press.

[43] Olweus, D. (2012b). Comments on cyberbullying article: A rejoinder. European Journal of Developmental Psychology.

[44] Patchin, J. W. (2012). Bullying beyond the schoolyard. Paper presented at the International Conference on Cyberbullying: Paris, France.

[45] Patchin, J. W., \& Hinduja, S. (2011). Traditional and non-traditional bullying among youth: A test of General Strain Theory. Youth and Society.

[46] Perren, S., Corcoran, L., Cowie, H., Dehue, F., Garcia, D., Mc Guckin, C., et al. (2012). Coping with cyberbullying: A systematic literature review.

[47] Sakellariou, T., Carroll, A., \& Houghton, S. (2012). Rates of cyber victimization and bullying among male Australian primary and high school students. School Psychology International.

[48] Shariff, S., \& Gouin, R. (2005). Cyberdilemmas: Gendered hierarchies, free expression and cyber-safety in schools.
[49] Smith, P. K., \& Slonje, R. (2010). Cyberbullying: The nature and extent of a new kind of bullying, in and out of school. Handbook of bullying in schools: An international perspective. New York, NY: Routledge.

[50] Smith, P. K. (2012b). Cyberbullying and cyber aggression. Handbook of school violence and school safety: International research and practice. New York, NY: Routledge.

[51] Shuttleworth, M. (2008). Qualitative Research Design. Retrieved from www.explorable.com.

[52] Tangen, D., \& Campbell, M. (2010). Cyberbullying prevention: One primary school's approach. Australian Journal of Guidance and Counselling.

[53] Tokunaga, R. S. (2010). Following you home from school: A critical review and synthesis of research on cyberbullying victimization. Computers in Human Behavior.

[54] Topc, C. \& Erdur-Baker, O. (2012). Affective and cognitive empathy as mediators of gender differences in cyber and traditional bullying. School Psychology International.

[55] Twemlow, S.W., Fonagy, P., Sacco, F. (2005). An innovative psychodynamically influenced approach to reduce school violence. J Amer Acad Child Adolescence Psychiatry.

[56] Vandebosch, H., \& Van, C.K. (2009). Cyberbullying among youngsters: Prevalence and profile of bullies and victims. New Media and Society.

[57] Van, M. M. (2005) Researching Lived Experience: Human science for an action sensitive pedagogy. London, Ontario: Althouse

[58] Volokh, A. (2000) Strategies to keep school safe. Retrieved from www.gulfnews.com.

[59] Wang, J., Ronald, J. I., and Jeremy, W. L. (2012). Patterns of Adolescent Bullying 
Behaviors: Physical, Verbal, Exclusion, Rumor, and Cyber. Journal of School Psychology.

[60] Wam. (2012). UAE tightens laws against cyber crimes. Retrieved from www.khaleej times.com

[61] Waters, J. (2013). Phenomenological Research Guidelines. Retrieved from www.capilano.uca.

[62] Willard, N. (2012). Cyberbullying and the law. Cyberbullying prevention and response: Expert perspectives. New York, NY: Routledge.

[63] Yilmaz, H. (2011). Cyberbullying in Turkish middle schools: An exploratory study. School Psychology International. 